\title{
The activation of $\mathrm{Cu}$ and $\mathrm{Al}$ by deuterons at energies up to $20 \mathrm{MeV}$
}

\author{
P. Bém ${ }^{1}$, L. Bittmann ${ }^{1}$, V. Burjan ${ }^{1}$, U. Fischer ${ }^{2}$, M. Götz ${ }^{1}$, M. Honusek ${ }^{1}$, V. Kroha ${ }^{1}$, J. Novák ${ }^{1}$, S. Simakov², \\ and E Šimčková ${ }^{1, a}$ \\ 1 Nuclear Physics Institute, 25068 Řež, Czech Republic \\ 2 Forchungszetrum Karlsruhe, Germany
}

\begin{abstract}
The proton and deuteron induced reaction have a great interest for the assessment of induced radioactivity of accelerator components. The IFMIF (International Fusion Material Irradiation Facility) accelerator needs such a data for estimation of the potential radiation hazards from the accelerating cavities and beam transport elements ( $\mathrm{Al}$, $\mathrm{Cu}, \mathrm{Fe}, \mathrm{Cr}, \mathrm{Nb}$ ). The cross sections are needed in the energy range from the threshold (2-10 MeV) up to $40 \mathrm{MeV}$ both for deuterons and protons. In order to investigate the first important nuclides relevant to the IFMIF, we have carried out the irradiation experiment with the variable-energy cyclotron U-120M of the Nuclear Physics Institute Řež. The production cross section of the nuclides $28-\mathrm{Al}, 27-\mathrm{Mg}, 24-\mathrm{Na}$ from reaction on 27-Al, further - the nuclides $64-\mathrm{Cu}$, $63-\mathrm{Zn}, 62-\mathrm{Zn}$ from reactions on $63-\mathrm{Cu}$ and the nuclides $65-\mathrm{Zn}, 65-\mathrm{Ni}$ from reactions on $65-\mathrm{Cu}$ were investigated by irradiation of aluminium and cuprum (natural isotope abundance) foil by deuteron beam of $20 \mathrm{MeV}$ energy. The stacked-foil technique was utilized. The absolute values of cross sections were calculated from the induced activities measured by calibrated HPGe detectors. The gamma-rays from the irradiated foils were analyzed by the DEIMOS code. The comparison of present results with data of other authors and with the prediction of different libraries is discussed.
\end{abstract}

\section{Introduction}

The proton and deuteron induced activation reaction have a great interest for the assessment of induced radioactivities in the accelerator components, targets and beam stopper. The cross sections are needed in the energy range from the threshold $(2-10 \mathrm{MeV})$ up to $40 \mathrm{MeV}$ both for deuterons and protons.

The variable energy NPI cyclotron provides protons and deuterons in energy range $11-37 \mathrm{MeV}$ and $11-20 \mathrm{MeV}$, respectively. We measured the cross section for deuteron induced reactions on $\mathrm{Al}$ and $\mathrm{Cu}$ by stacked-foil technique and its absolute values were calculated from the measured induced activities.

\section{Experiment arrangement}

The high purity natural $\mathrm{Al}$ and $\mathrm{Cu}$ foils (Goodfellow product) were bombarded by deuterons from the U-120M cyclotron working in the negative-ion mode of acceleration. Initial deuteron energy was $20.4(0.2) \mathrm{MeV}$. The thickness of $\mathrm{Al}$ and $\mathrm{Cu}$ foils was $50 \mu \mathrm{m}$ and $25 \mu \mathrm{m}$, respectively.

We carried out two experiments. In the experiment A the stock of eleven $\mathrm{Al}$ and eleven $\mathrm{Cu}$ foils placed by turns was bombarded by deuteron beam of mean current $0.09 \mu \mathrm{A}$ during exposition time of $15 \mathrm{~min}$. The irradiation time and the beam current in the experiment B was 5 min and $0.33 \mu \mathrm{A}$, respectively. Beam current was registered every $5 \mathrm{~s}$ and stocked in PC to restore history.

Immediately (after $8 \mathrm{~min}$ ) the activities of the irradiated foils were measured by two calibrated HPGe detectors of 23 and $50 \%$ efficiency and of FWHM $1.8 \mathrm{keV}$ at $1.3 \mathrm{MeV}$. The PC registered beam current and the $\mathrm{PC}$ measured sample activities were time synchronized.

\footnotetext{
${ }^{a}$ Presenting author, e-mail: simeckova@ujf.cas.cz
}

\section{Cross section calculation}

The energy of reaction in subsequent foils was calculated by using SRIM 2003 code.

The gamma-rays from irradiated samples were investigated with HPGe detectors and analyzed by the DEIMOS code. Activated isotopes were identified on the basis of $\mathrm{T}_{1 / 2}, \gamma$ ray energies and intensities. The characteristics of the isotopes observed from irradiated $\mathrm{Al}$ and $\mathrm{Cu}$ foil are in table 1 and table 2 , respectively.

Table 1. Isotopes observed from irradiated Al foils.

\begin{tabular}{lcll}
\hline Isotope & $\mathrm{T}_{1 / 2}$ & \multicolumn{1}{c}{$\mathrm{E}_{\gamma}$} & \multicolumn{1}{c}{$\mathrm{I}_{\gamma}$} \\
\hline${ }^{24} \mathrm{Na}$ & $14.9590 \mathrm{~h}$ & $1368.633 \mathrm{keV}$ & $100 \%$ \\
& & $2754.028 \mathrm{keV}$ & $99.944 \%$ \\
\hline${ }^{27} \mathrm{Mg}$ & $9.458 \mathrm{~m}$ & $843.74 \mathrm{keV}$ & $71.8 \%$ \\
& & $1014.42 \mathrm{keV}$ & $28.0 \%$ \\
\hline${ }^{28} \mathrm{Al}$ & $2.2414 \mathrm{~m}$ & $1778.969 \mathrm{keV}$ & $100 \%$ \\
\hline
\end{tabular}

Table 2. Isotopes observed from irradiated $\mathrm{Cu}$ foils.

\begin{tabular}{llll}
\hline Isotope & \multicolumn{1}{c}{$\mathrm{T}_{1 / 2}$} & \multicolumn{1}{c}{$\mathrm{E}_{\gamma}$} & \multicolumn{1}{c}{$\mathrm{I}_{\gamma}$} \\
\hline${ }^{65} \mathrm{Zn}$ & $244.36 \mathrm{~d}$ & $1115.546 \mathrm{keV}$ & $50.60 \%$ \\
${ }^{64} \mathrm{Cu}$ & $12.700 \mathrm{~h}$ & $1345.84 \mathrm{keV}$ & $0.473 \%$ \\
\hline${ }^{62} \mathrm{Zn}$ & $9.186 \mathrm{~h}$ & $596.56 \mathrm{keV}$ & $26 \%$ \\
& & $548.35 \mathrm{keV}$ & $15.3 \%$ \\
\hline${ }^{65} \mathrm{Ni}$ & $2.5172 \mathrm{~h}$ & $1481.84 \mathrm{keV}$ & $24 \%$ \\
\hline${ }^{63} \mathrm{Zn}$ & $38.47 \mathrm{~m}$ & $669.62 \mathrm{keV}$ & $8 \%$ \\
& & $962.06 \mathrm{keV}$ & $6.5 \%$ \\
\hline
\end{tabular}

The measured activities were corrected for decay during the irradiation. The dependence of isotope generation on the 


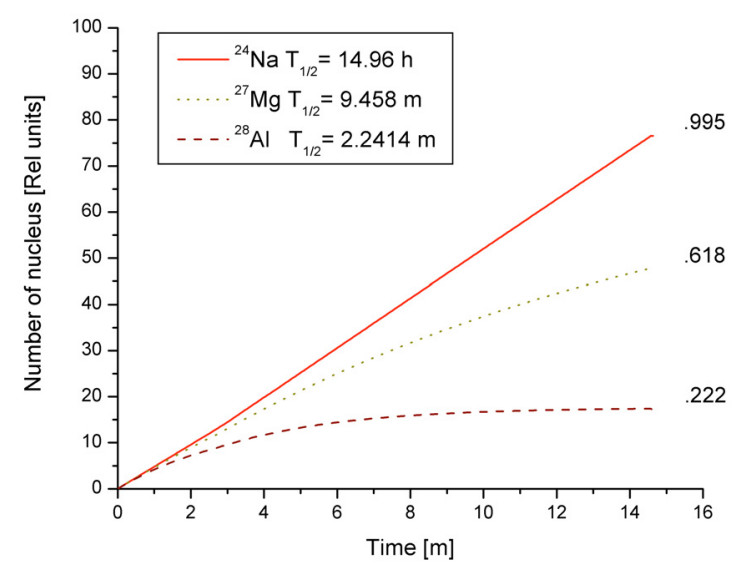

Fig. 1. The dependence of the nucleus generation on the irradiation time - Experiment A, beam current $0.09 \mu \mathrm{A}$. The values on the right are correction factor.

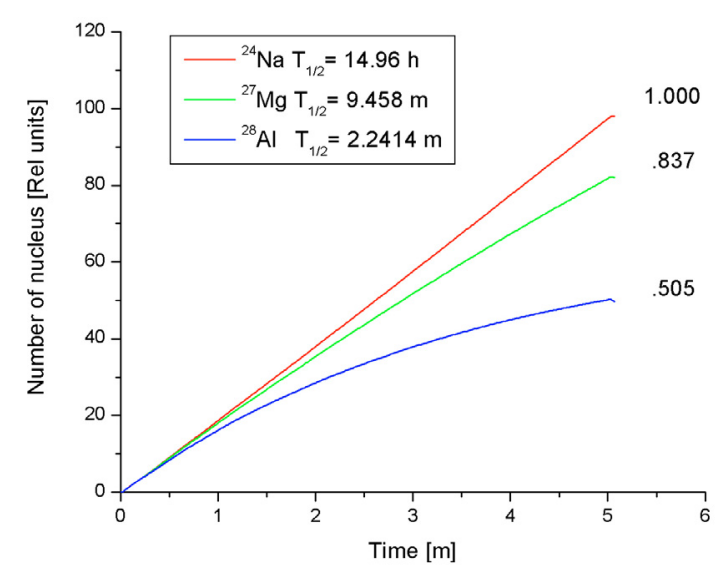

Fig. 2. The dependence of the nucleus generation on the irradiation time - Experiment B, beam current $0.33 \mu \mathrm{A}$. The values on the right are correction factor.

duration of the irradiation for experiment $\mathrm{A}$ and experiment $\mathrm{B}$, is shown in the figure 1 and figure 2 , respectively.

Systematic errors of experimental data of cross section are composed of current uncertainty (about 10\%), uncertainty of foil thickness (5\%) and initial energy determination 1\%. Mean statistical error in activity determination is $3 \%$.

\section{Results}

\subsection{Cross section for $\mathrm{Al}(\mathrm{d}, \mathrm{x})$ reactions}

Natural aluminium consists of ${ }^{27} \mathrm{Al}$ isotope only. In the figure 3, the widely known values of the cross sections for the $(\mathrm{d}, \mathrm{p} \alpha)$ reaction on ${ }^{27} \mathrm{Al}$ are shown. Our data are compared to the data of other authors from EXFOR database.

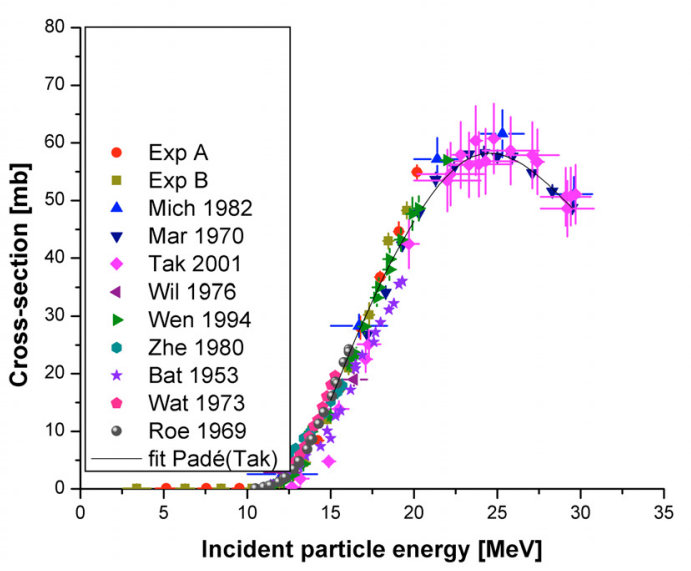

Fig. 3. Reaction ${ }^{27} \mathrm{Al}(\mathrm{d}, \mathrm{p} \alpha)^{24} \mathrm{Na}$. Results of present cross section measurement with data from EXFOR database are compared. The line is the "fit Padé", ref. [1].

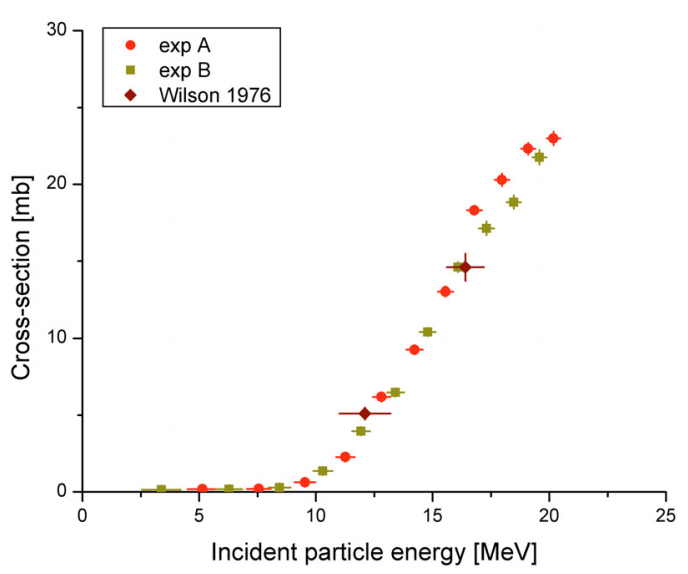

Fig. 4. Cross section of the reaction ${ }^{27} \mathrm{Al}(\mathrm{d}, 2 \mathrm{p})^{27} \mathrm{Mg}$.

The cross section of ${ }^{27} \mathrm{Mg}$ and ${ }^{28} \mathrm{Al}$ products with half life in a range of minutes was measured as well, see figure 4 and figure 5 .

\subsection{Cross section for $\mathrm{Cu}(\mathrm{d}, \mathrm{x})$ reaction}

The natural cupper has two stable isotopes $-69.2 \%$ of ${ }^{63} \mathrm{Cu}$ and $30.8 \%$ of ${ }^{65} \mathrm{Cu}$. The generation of the ${ }^{65} \mathrm{Zr}$ by irradiation of the natural cupper may proceed in two contributing reactions: radioactive capture ${ }^{63} \mathrm{Cu}(\mathrm{d}, \gamma)$ and ${ }^{65} \mathrm{Cu}(\mathrm{d}, 2 \mathrm{n})$ reaction, as well. The radioactive capture reaction cross section is known to be very small. Hence, the ${ }^{63} \mathrm{Cu}(\mathrm{d}, \gamma)$ reaction, for which the Q-value is as large as $13.5 \mathrm{MeV}$, would not be expected to contribute appreciably to the measured yield of ${ }^{65} \mathrm{Zn}$. The cross section values for the reaction ${ }^{65} \mathrm{Cu}(\mathrm{d}, 2 \mathrm{n})$ compared with other authors from EXFOR database. 


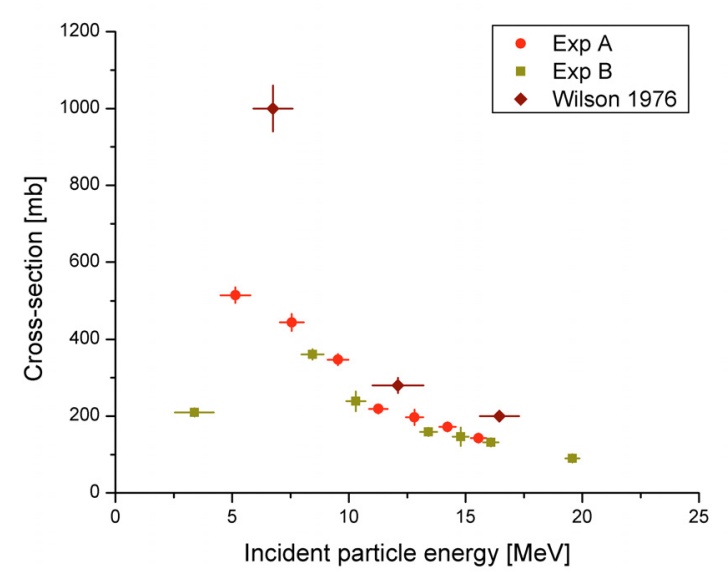

Fig. 5. Cross section for the reaction ${ }^{27} \mathrm{Al}(\mathrm{d}, \mathrm{p})^{28} \mathrm{Al}$.

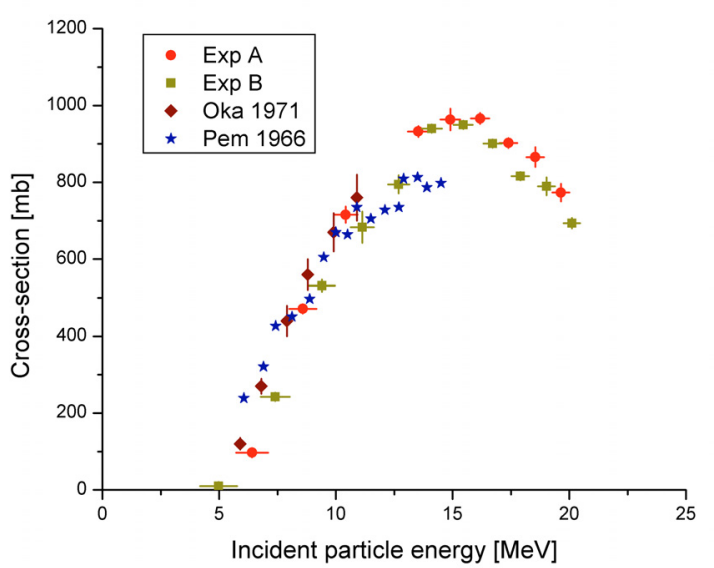

Fig. 6. Cross section for the reaction ${ }^{65} \mathrm{Cu}(\mathrm{d}, 2 \mathrm{n}){ }^{65} \mathrm{Zn}$.

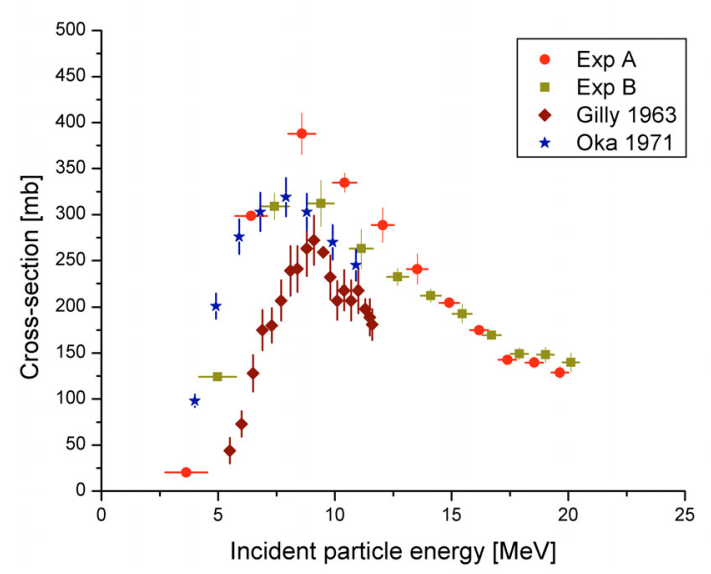

Fig. 7. Cross section for the reaction ${ }^{63} \mathrm{Cu}(\mathrm{d}, \mathrm{p}){ }^{64} \mathrm{Cu}$.

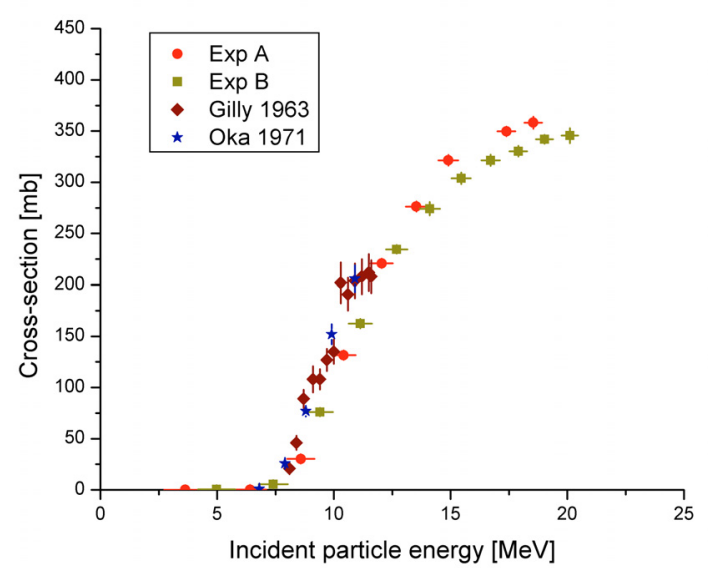

Fig. 8. Cross section for the reaction ${ }^{63} \mathrm{Cu}(\mathrm{d}, 2 \mathrm{n}){ }^{63} \mathrm{Zn}$.

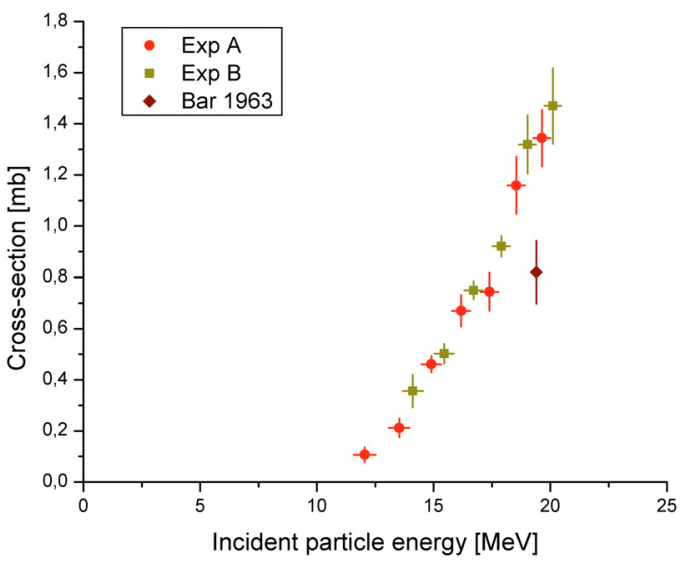

Fig. 9. Cross section for the reaction ${ }^{65} \mathrm{Cu}(\mathrm{d}, 2 \mathrm{p})^{65} \mathrm{Ni}$.

Similar case stems for the ${ }^{64} \mathrm{Cu}$ isotope, which can originate in the ${ }^{63} \mathrm{Cu}(\mathrm{d}, \mathrm{p})$ reaction (threshold $0.0 \mathrm{MeV}$ ), and also in the ${ }^{65} \mathrm{Cu}(\mathrm{d}, \mathrm{t})$ reaction. Fulmer in ref. [2] has claimed that the yield of ${ }^{64} \mathrm{Cu}$ production exhibits two humps that are due to contribution of those two reactions. He ascribed the first hump to the ${ }^{63} \mathrm{Cu}(\mathrm{d}, \mathrm{p})$, which occurred with a $\mathrm{Q}$-value of $5.7 \mathrm{MeV}$. The higher energy hump (with $\mathrm{E}>20 \mathrm{MeV}$ ) is apparently due to the ${ }^{65} \mathrm{Cu}(\mathrm{d}, \mathrm{t})$. Because of our initial deuteron energy was less $20 \mathrm{MeV}$, we may presume, that contribution of the ${ }^{65} \mathrm{Cu}(\mathrm{d}, \mathrm{t})$ reaction is irrelevant and ascribed our results to the ${ }^{63} \mathrm{Cu}(\mathrm{d}, \mathrm{p})$, figure 7 .

There is only one possible way to generate ${ }^{63} \mathrm{Zn}$ in the energy region up to $20 \mathrm{MeV}$, namely the ${ }^{63} \mathrm{Cu}(\mathrm{d}, 2 \mathrm{n})$ reaction (shown in fig. 8).

The isotope ${ }^{65} \mathrm{Ni}$ could be generated only in the ${ }^{65} \mathrm{Cu}(\mathrm{d}, 2 \mathrm{p})$ reaction. Results of our measurement are shown in figure 9, where only one value cited in EXFOR database is given for the comparison.

The only possible way for generation of the ${ }^{62} \mathrm{Zn}$ isotope in energy region $\left(\mathrm{E}_{\mathrm{d}}<20 \mathrm{MeV}\right)$ is the ${ }^{63} \mathrm{Cu}(\mathrm{d}, 3 \mathrm{n})$ reaction, results are shown in figure 10. 


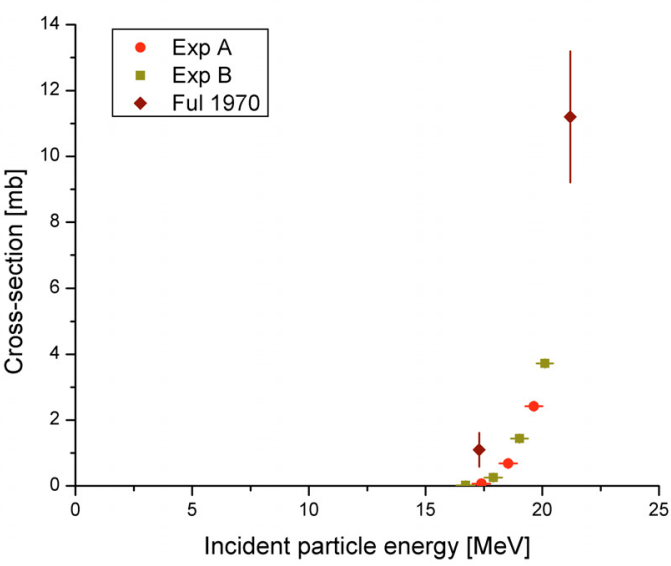

Fig. 10. Cross section for the reaction ${ }^{63} \mathrm{Cu}(\mathrm{d}, 3 \mathrm{p})^{62} \mathrm{Zn}$.

\section{Conclusion}

The cross section values for $(\mathrm{d}, \mathrm{x})$ reaction on natural $\mathrm{Al}$ and $\mathrm{Cu}$ were determined for the reactions ${ }^{27} \mathrm{Al}(\mathrm{d}, \mathrm{p} \alpha)^{24} \mathrm{Na}$, ${ }^{27} \mathrm{Al}(\mathrm{d}, 2 \mathrm{p}){ }^{27} \mathrm{Mg},{ }^{27} \mathrm{Al}(\mathrm{d}, \mathrm{p}){ }^{28} \mathrm{Al},{ }^{65} \mathrm{Cu}(\mathrm{d}, 2 \mathrm{n}){ }^{65} \mathrm{Zn},{ }^{63} \mathrm{Cu}(\mathrm{d}, \mathrm{p}){ }^{64} \mathrm{Cu}$, ${ }^{63} \mathrm{Cu}(\mathrm{d}, 2 \mathrm{n}){ }^{63} \mathrm{Zn},{ }^{65} \mathrm{Cu}(\mathrm{d}, 2 \mathrm{p}){ }^{65} \mathrm{Ni}$ and ${ }^{63} \mathrm{Cu}(\mathrm{d}, 3 \mathrm{n}){ }^{62} \mathrm{Zn}$ at the deuteron energy up to $20 \mathrm{MeV}$.

The agreement with well determined data (EXFOR database) support the reliability of present results of cross section data for deuteron induced reaction up to $20 \mathrm{MeV}$.

\section{References}

1. S. Takàcs et al., Nucl. Instrum. Meth. B 174, 232 (2001).

2. C.B. Fulmer et al., Nucl. Phys. A 155, 40 (1970). 